\title{
GERAKAN ANTI NARKOBA DAN GEMAR WIRAUSAHA BAGI PEMUDA DI TONDANO MINAHASA
}

\author{
Nikolas F. Wuryaningrat \\ Fakultas Ekonomi Universitas Negeri Manado
}

\begin{abstract}
ABSTRAK
Data dari Badan Narkotika Nasional menyebutkan Sulawesi Utara merupakan lima besar pengguna narkoba di Indonesia naik dari peringkat Sembilan hanya satu tahun saja (2014-2105) yang 70\% pemakainya adalah pada usia muda. Kemudian data dari Dinas Sosial Minahasa, Kabupaten Minahasa merupakan pengguna terbesar ketiga di Sulawesi Utara. Oleh karenanya angka pemakaian narkobanya cukup tinggi dan terus meningkat dari tahun ke tahun dan perlu dicarikan solusinya.Selain itu pemerintah saat ini sedang gencar-gencarnya berusaha agar generasi bangsa Indonesia tidak lagi bertumpu pada orang lain untuk mendapatkan pekerjaan. Akan tetapi mampu dan berani mengambil risiko untuk membangun usaha sendiri. Oleh karena itulah peran dunia pendidikan sangat vital untuk menumbuhkan serta mengembangkan semangat wirausaha. Pendidikan kewirausahaan yang diintegrasikan kedalam sistem pendidikan akan berpotensi mendukung pertumbuhan ekonomi.Mengacu pada hal tersebut maka akan dikombinasikan cara pengentasan narkoba di Sulawesi Utara dan Kabupaten Minahasa sebagai pilot project-nya dengan pelatihan dan motivasi untuk menggugah masyarakat usia muda untuk berwirausaha, hal ini diharapkan memberi manfaat agar pengguna atau kaum muda yang belum terkena narkoba dapat mengalih perhatiannya pada dunia narkoba dengan dunia bisnis. Pada gilirannya masalah lain dari Kabupaten Minahasa yang angka sarjananya masih mengganggur tinggi bisa ikut teratasi jika angka penyalahgunaan narkoba berkurang dan semangat wirausahannya bisa ditingkatkan. Mitra GSPdi Tondano dilibatkan karena atas permintaan mereka agar basis jemaat rentang pemuda dan remaja memperoleh pengetahuan yang cukup untuk mencegah narkoba masuk ke kalangan jemaat pemuda dan remaja. Mitra memfasilitasi kegiatan ini dengan memberikan bantuan sarana dan prasarana yang bisa mendukung kegiatan ini.
\end{abstract}

\section{PENDAHULUAN}

\subsection{Analisis Situasi}

Mitra GSPdi adalah salah satu organisasi gereja yang besar di Indonesia dan sudah diakui oleh negara sebagai organisasi yang legal yang sudah berdiri banyak cabang di daerah-daerah. Dalam hal ini Gereja Sidang Pantekosta di Indonesia (GSPDI) Wilayah Tomohon Tondano adalah mitra kami yang membawahi dua gereja GSPDI di Tomohon dan Tondano, khususnya di Perum Unima. Mitra kami sangat konsisten dalam membantu perkembangan pemuda di Gereja, karena dipercaya Pemuda dan Remaja adalah cikal bakal dari penerus gereja di masa depan. Salah satu permasalahan besar yang dialami oleh pemuda di Tondano adalah masalah maraknya penggunaan narkoba dan tinggi pengangguran terdidik. GSPDI untuk pertama kalinya ingin melakukan kegiatan gerakan anti narkoba di kalangan pemuda di Tomohon-Tondano.

Untuk membantu misinya menyelematkan generasi muda dari narkoba maka mereka butuh bantuan dari dunia akademik guna mencari solusi gerakan anti narkoba yang lebih baik dan inovatif. Di bawah ini adalah salah satu gerakan anti narkoba yang dijalankan dan salah satu kasus narkoba yang ditangani kepolisian Minahasa.

Kegiatan ini akan diprakarsai oleh wilayah Tondano di karenakan gereja ini sebagian besar jemaatnya masih berusia muda. Kota Tondano sebagai ibukota Kabupaten Minahasa merupakan daerah salah satu daerah dengan perkembangan ekonomi yang cukup pesat di Kabupaten Minahasa. Seperti kebanyakan ibukota di 
daerah lain penduduknya berasal dari berbagai daerah di Sulawesi Utara dan daerah lainnya. Jaraknya yang cukup dekat dengan Kampus Universitas negeri Manado (Unima) menjadikan penduduknya lebih beragam dikarenakan banyak mahasiswa di Unima berasal dari seluruh daerah di Sulawesi Utara dan daerah lainnya di Indonesia.

Kota Tondano Kabupaten Minahasa dengan keberagamnya memiliki beberapa masalah, contohnya cukup tingginya angka penyalahgunaan narkoba. BNN Provinsi Sulut menempatkan Kabupaten Minahasa sebagai tiga besar pemakai narkoba dan minuman keras di Provinsi Sulawesi Utara. Sulawesi Utara sendiri merupakan lima besar nasional penyalahgunaan noarkoba, sehingga bisa dibayangkan dahsyatnya bahaya narkoba bagi masyarakat. Selain itu Badan Narkotika Sulawesi Utara juga menjelaskan 70 persen pengguna narkoba dan minuman keras adalah di usia pelajar dan mahasiswa. Pelajar dan mahasiswa berada pada usia muda, usia yang rentan pada penyalahgunaan narkoba. Berikut ini adalah data dan fakta mengenai perkembangan pesat penyalahgunaan narkoba nasional.

Tabel 1. Pengguna Narkoba

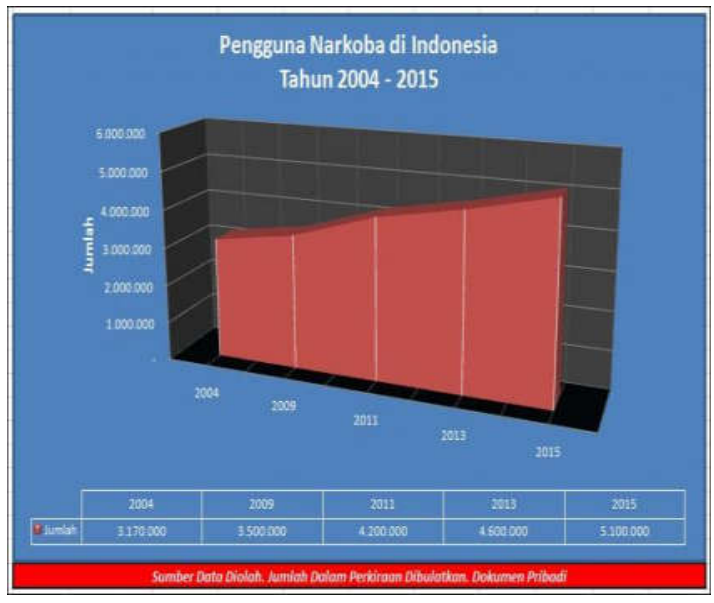

Selain itu data yang dilansir oleh berita antara menyatakan pada tahun 2016 tercatat rata-rata angka pengangguran di Sulawesi Utara $9.03 \%$, lebih tinggi dari rata-rata nasional. Walaupun tidak diperoleh data jumlah pengangguran di Kabupaten Minahasa, tetapi melihat fakta data di Sulawesi Utara maka dapat dipastikan angka pengangguran di Minahasa kemungkinan besar cukup tinggi. Menurut data yang diperoleh dari BNN yang dilansir dari berbagai media nasional (salah satunya Pikiran Rakyat) penggangguran relative lebih rentan menjadi pemakai narkoba. Tercatat dari sekitar 100 orang pengguna narkoba tujuh puluhan diantaranya adalah berstatus penggangguran. Oleh karenanya narkoba bisa menjadi ancaman bagi pemuda khususnya yang sudah menyelesaikan pendidikannya di perguruan tinggi jika terlalu lama terus menganggur.

Melihat realitas diatas, maka perlu dilakukan gerakan semangat kewirausahaan yang kuat dan terus menerus, untuk menggugah pemuda dapat memiliki sikap dan jiwa kewirausahaan sebagai solusi mengatasi pengangguran dan mengurangi dampak negative dari penyalahgunaan narkoba.

\section{TEORI DAN SOLUSI}

\subsection{Solusi Permasalahan}

Beberapapenelitian

sebelumnyamenyebutkan bahwa keinginan berwirausahaparapemudamerupakan

sumber bagi lahirnyawirausahawirausahamasadepan(Gorman et al., 1997; Kourilsky dan Walstad, 1998). Sikap, perilaku dan pengetahuanmerekatentang kewirausahaan akanmembentuk kecenderunganmereka untukmembuka usaha-usaha baru dimasa mendatang. Penelitian untukmelihat aspek intensi kewirausahaan seseorang telahmendapat perhatiancukup besar dari para peneliti. Intensi kewirausahaan dapat diartikan sebagai proses pencarian informasi yang dapat digunakan untukmencapai tujuanpembentukan suatu usaha (Katz dan Gartner, 1988 dalam Indarti 2008). Seseorang denganintensi untukmemulai usaha akanmemiliki kesiapan dan kemajuan yang lebih baik dalam usahayang dijalankan dibandingkan seseorangtanpaintensiuntukmemulai usaha. Seperti yang dinyatakan oleh Krueger dan Carsrud (1993 dalam Indarti 2008), intensi telahterbuktimenjadi prediktor yang terbaik bagi perilaku kewirausahaan. Olehkarena itu, intensi dapatdijadikan sebagaipendekatan dasar yang masuk akal untukmemahamisiapa-siapa yang akanmenjadiwirausaha (Choo dan Wong, 
2006 dalam Indarti 2008).

Mengacu pada kajian teori diatas maka solusi yang ditawarkan adalah memberikan sosialisasi dalam bentuk penyuluhan dan pelatihan kewirausahaan yang akan menghadirkan pakar-pakar kewirausahaan dari dunia akademisi dan dunia praktis usaha serta motivator handal. Kehadiran pribadi - pribadi tersebut diharapkan bisa memberikan pencerahan dan peningkatan intensi kewirausahaan bahwa untuk berhasil tidak melulu harus dari dunia kerja, tetapi sukses bisa lebih bermaksana dengan membangun dunia kerja itu sendiri.

Dikarenakan kegiatan ini juga berhubungan dengan gerakan anti narkoba, maka penyuluhan tentang bahaya narkoba menjadi bagian yang tidak terpisahkan. Penyuluhan ini nantinya akan dilakukan oleh ahli yang khusus membidangi masalah narkotika. Direncanakan pihak BNN Provinsi Sulut akan dihadirkan untk memberikan pencerahan tentang bahaya narkoba jika disalah gunakan.

\section{METODE PELAKSANAAN Metode Solusi Permasalahan}

Metoda yang ditawarkan dalam pemecahan masalah di atas adalah melalui pencerahan gerakan anti narkoba dan peningkatan intensi kewirausahaan. Narkoba sudah menjadi ancaman bangsa karena salah satu incarannya generasi muda dan pengangguran yang juga masih muda. Oleh karena itu solusi yang akan dihadirkan adalah dengan membuka kesadaran masyarakat akan bahaya narkoba dikombinasikan dengan penyuluhan dan pelatihan kewirausahaan untuk meningkatkan intensi kewirausahaan pemuda. Dengan kata lain penyuluhan dan pelatihan ini diharapkan bisa menjadi cara yang jitu untuk dua masalah sekaligus, yaitu untuk mengalih perhatian pada narkoba dan merubah mental job seeker menjadi job creator yang jika berhasil akan mengurangi pengangguran.

Menurut para pakar untuk mengurangi resiko ancaman narkoba bisa dilakukan dengan cara memperbanyak aktivitas untuk mengalihkan perhatiannya pada dunia narkoba. Jika pemuda sibuk dengan pekerjaannya berwirausaha maka diharapkan dapat mengalihkan perhatiannya pada dunia narkoba, selain itu jika berhasil dan mau terus berupaya mengambil resiko sebagai wirausahawan maka status pengangguran yang mungkin dipegangnya akan hilang dan akan lebih banyak membantu sesama untuk membuka lapangan pekerjaan. Dengan kata lain, metoda ini disebut metoda 'brainwash' pemuda dengan usaha peningkatan intensi kewirausahaan diharapkan akan menjadi alih perhatian pada dunia narkoba yang pada gilirannya bisa mengurangi jumlah pengangguran.

Bagian akhir dari metoda ini adalah tahap evaluasi keberhasilan metoda ini. Keberhasilannya akan diukur melalui perangkat alat ukur intensi kewirausahaan melalui kuesioner yang sudah diuji terlebih dahulu validitas dan reliabilitasnya. Evaluasi dibagi menjadi dua tahap evaluasi. Tahap pertama adalah evaluasi saat selesai kegiatan. Tahap evaluasi kedua yaitu dua minggu setelah kegiatan, sekalian melihat implementasi hasil pelatihan.

\section{HASIL YANG DICAPAI}

Narkoba adalah ancaman serius bangsa Indonesia. Oleh karenanya perlu usaha yang serius untuk menanggulangi ataupun mencegah narkoba semakin meningkat penggunannya. Pencegahan narkoba bukan saja kewajiban aparat pemerintah tetapi juga kewajiban bagi seluruh lapisan masyarakat. Peserta kegiatan ini sebanyak 20 orangg pemuda remaja yang terdiri dari jemaat sendiri (Tomohon-Tondano), jemaat tetangga dan dari keyakinan lain. Undangan sebenarnya diharapkan 40 orang, tetapi karena keterbatasan lokasi gereja yang masih gereja yang menggunakan rumah pribadi yang lantai dua adalah rumah kos yang hanya terdiri dari 6 kamar maka untuk menampung peserta lebih dari 20 tiidak memungkinkan.

Dalam kegiatan pencegahan narkoba ini, mengandung hal kebaruan dengan tidak hanya menitik beratkan pada penyuluhan tentang bahaya narkoba. Hal tersbut bukannya tidak efektif, tetapi terkesan monoton dan kurang menarik atau menggugah minat menyalurkan aktivitas untuk melupakan narkoba. Oleh karena itu

$$
\mathrm{P} \text { a g e } 16 \text { | } 75
$$


selain dilakukan penyuluhan narkoba, dilakukan pula pelatihan kewirausahaan sampai para pemuda dan remaja bisa atau menghasilkan sesuatu hal yang menarik untuk diproduksi bahkan di pasarkan. Dibawah ini adalah proses kegiatan ini yang dapat dilihat pada gambar 3 .

Gambar 3. Proses Kegiatan

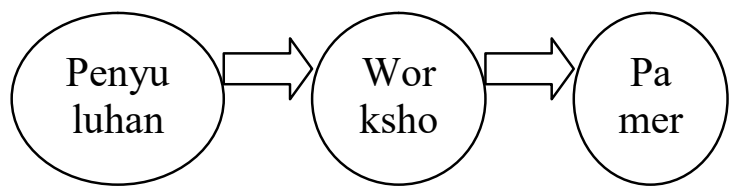

Gambar diatas menggambarkan bahwa penyuluhan diberikan untuk memberi pengetahuan yang cukup akan bahaya narkoba dan akibat atau dampak negative dari narkoba, disertai kesaksian yang tertulis atau terdokumentasikan dalam bentuk video dari mantan pengguna narkoba yang berhasil keluar dari linbgkaran setan narkoba, dan menjadi manusia atau pribadi yang takut akan Tuhan. Kemudian langkah kedua adalah memberikan workhop berupa pengembangan kreativitas dan inovasi dari pemuda remaja berwirausaha dan menghasilkan suatu produk yang menarik dari bahan-bahan yang sederhana yang sudah disiapkan oleh panitia. Kemudian memanfaatkan pameran kewirausahaan yang diselengaraakan oleh Unima maka produk yang dihasilkan oleh para peserta dipamerkan, kebetulan sebagian besar peserta adalah mahasiwa dari Unima dari berbagai fakultas. Kegiatan diatas berhasil diilakukan selama 3 hari, 2 malam, peserta dikarantina dan diinapkan, untuk memberikan apa yang diisebut sebagai 'brainwash'.

Kegiatan ini menghasilkan adanya tambahan pengetahuan bagi pemuda dan remaja dalam bahaya narkoba dan juga peningkatan kemampuan dan kemauan mereka dalam beriwirausaha. Bedasarkan hasil evaluasi, pelatihan ini cukup berhasil namun terdapat beberapa hambatan pada saat pelatihan, yaitu kurangnya fasilitas alat peraga dan proyektor untuk menampilkan presentasi, sehingga kegiatan lebih fokus pada pengisian atau pemberian informasi tanpa slide presentasi dan lebih pada pendekatan persuasive perorangan yang dibantu oleh panitia dan narasumber luar. Pemuda remaja peserta sangat antusias dalam merespon kegiatan ini. Hal ini terbukti pada keinginan dari pemuda remaja untuk terus fokus pada materi yang diberikan walaupun harus dilakukan kegiatan tanpa terputus di tempat mereka diinapkan dan banyak memberi pertanyaan,saran dan masukan. Bahkan antusias kegiatan ini diikuti pula oleh pemuda/remaja dari jemaat lain dan dari keyakinnan lain.

\section{KESIMPULAN DAN SARAN Kesimpulan}

Dapat disimpulkan kegiatan ini menghasilkan adanya tambahan pengetahuan bagi pemuda dan remaja dalam bahaya narkoba dan juga peningkatan kemampuan dan kemauan mereka dalam beriwirausaha. Bedasarkan hasil evaluasi, pelatihan ini cukup berhasil namun terdapat beberapa hambatan pada saat pelatihan, yaitu kurangnya fasilitas alat peraga dan proyektor untuk menampilkan presentasi, sehingga kegiatan lebih fokus pada pengisian atau pemberian informasi tanpa slide presentasi dan lebih pada pendekatan persuasive perorangan yang dibantu oleh panitia dan narasumber luar. Pemuda remaja peserta sangat antusias dalam merespon kegiatan ini. Hal ini terbukti pada keinginan dari pemuda remaja untuk terus fokus pada materi yang diberikan walaupun harus dilakukan kegiatan tanpa terputus di tempat mereka diinapkan dan banyak memberi pertanyaan,saran dan masukan. Bahkan antusias kegiatan ini diikuti pula oleh pemuda/remaja dari jemaat lain dan dari keyakinnan lain.

\section{Saran}

Saran dalam kegiatan ini adalah sebagai berikut: yaitu:

1. Mitra dalam hal ini harus dapat membangun komitmen bbersama bukan hanya komitmen jangka pendek saat kegiatan, tetapi komitmen jangka panjang untuk menjamin keberlanjutan program ini ataupun bahkan program kegiatan lainya.

2. Pendanaan multi years untuk 
kegiatan yang seharusnya bisa menjadi kegiatan yang berkelanjutan.

\section{DAFTAR PUSTAKA}

Choo, S., dan M. Wong, 2006. "Entrepreneurial intention:triggersand barriers to new venture creations in Singapore".Singapore Management Review28 (2): 47-64.

Cromie, S., 2000. "Assessing entrepreneurial inclinations: someapproaches and empiricalevidence".European

Journal of Workand Organizational Psychology 9 (1): 7-30.

Dalton, dan Holloway, 1989. "Preliminaryfindings: entrepreneur study". Working paper, BrighamYoung University.

Duh, M., 2003. "Familyenterprises as an important factorof the economic development: the case of Slovenia".Journal of EnterprisingCulture 11 (2): 111-130. Global Entrepreneurship Monitor (GEM) Report, 2006. London Business School.

Giles, M., dan A. Rea, 1970. "Careerselfefficacy: an application of the theoryof planned behavior".Journal of

Occupational\&OrganizationalPsych ology 73

(3):393-399.

Gorman, G., D. Hanlon, dan W.King, 1997. "Entrepreneurship education: the Australian perspective forthe nineties".Journal of Small Business Education9: 1-14.

Hacket,G.danN.E.Betz,1986.“Applicationo fself-efficacytheorytounderstanding career choicebehavior". Journal of Social Clinical and Phsycology4: 279-289.

Helms,MarilynM.,2003.“Japanesemanagers :theircandidviewsonentrepreneurship ". CR 13 (1): 24-34.

Indarti, N., 2004. "Factors affecting entrepreneurial intentions among Indonesian students".Jurnal Ekonomi dan Bisnis 19 (1): 57-70.

Katz, J., dan W. Gartner, 1988. "Properties of emerging organizations".Academy of

Management Review13 (3): 429-441.

Kolvereid, L., 1996. "Prediction of employmentstatuschoice intentions".

Entrepreneurship Theory and Practice 21 (1): 47-57.

Kourilsky, M. L. dan W. B. Walstad, 1998. Entrepreneurship and femaleyouth: knowledge,attitude,gender

differences, and educational practices".Journal of Business Venturing 13 (1): 77-88.

Kristiansen, S, 2002. "Individual perception of business contexts: the case ofsmall-scale entrepreneurs in Tanzania".Journal of Developmental Entrepreneurship 7 (3).

Kristiansen, S., B. Furuholt, dan F. Wahid, 2003. "Internet cafe entrepreneurs: pioneers in informationdissemination in Indonesia". The International Journal of Entrepreneurship and Innovation 4 (4): 251-263.

Krueger, N. F. dan A. L. Carsrud, 1993. "Entrepreneurialintentions: applying the theory of planned behavior".Entrepreneurship \&Regional Development5 (4): 315 330 .

Mazzarol, T., T. Volery, N. Doss, danV. Thein, 1999. "Factors influencing small business start-ups". International Journal of Entrepreneurial Behaviour and Research 5 (2): 48-63.

McClelland, D., 1961. The Achieving Society, Princeton, New Jersey: Nostrand.

McClelland, D., 1971. The Achievement Motive in Economic Growth, in: P. Kilby(ed.) Entrepreneurship and Economic Development, New York The Free Press, 109-123. Mathews, C. H. dan S. B. Moser, 1996. "A longitudinal investigation of the impact of familybackground and gender on interest in small firmownership". Journal of Small Business Management 34 (2): 29-43.

Mead, D. C. dan C. Liedholm, 1998. "The dynamics ofmicro and small enterprise in developingcountries". World 
Development 26 (1): 61-74.

Meier, R. dan M. Pilgrim,1994. "Policyinduced constraints on small enterprise development in Asiandevelopingcountries". Small EnterpriseDevelopment5 (2):66-78.

Nunally, J. C., 1978.Psychometric Theory. New York: McGraw-Hill.

Remenyi, D., B. Williams, A. Money, dan E. Swartz, 2000.Doing Research in Business and Management: An Introduction to Process and Method. London: Sage Publications.

Reynolds, P. D., M. Hay, W. D. Bygrave,S. M. Camp, dan E. Aution, 2000. "Global entrepreneurshipmonitor:executive report". A Research Report from Babson College, Kauffman Center for Entrepreneurial Leadership, and London Business School.

Sabbarwal,1994. "Determinants of entrepreneurial start-ups: a studyof industrial units in India". Journal of Entrepreneurship3 (1).

Scapinello, $\mathrm{K}$. F., 1989."Enhancingdifferencesintheach ievement attributions of high and lowmotivation groups".Journal of Social Psychology129 (3): 357-363.

Schiller, B.R., dan P. E. Crewson, 1997. "Entrepreneurialorigins:

alongitudinalinquiry". Economic Inquiry35 (3): 523-531.

Scott, M. dan D. Twomey, 1988. "The long-termsupplyof entrepreneurs: students' career aspirations in relation to entrepreneurship". Journal of Small Business Management26 (4): 5-13.

Sengupta, S. K. dan S. K. Debnath, 1994. "Needforachievement and entrepreneurial success: a studyofentrepreneurs in two rural industriesin West Bengal".The Journal of Entrepreneurship 3 (2): 191-204.

Sinha, T. N., 1996. "Human factors inentrepreneurship effectiveness". Journal of

Entrepreneurship 5 (1): 23-29.

Steel, D., 1994. "Changing the institutionalandpolicyenvironment for small enterprise development in
Africa". Small Enterprise

Development 5 (2): 4-9.

Swierczek, F. W., dan T. T. Ha, 2003. "Entrepreneurial orientation, uncertainty avoidance and firmperformance: ananalysis of Thai and VietnameseSMEs". International Journal of Entrepreneurship and Innovation 4 (1): 46-58.

Tkachev, A., dan L. Kolvereid, 1999. "Self-employment intentions among Russian students". Entrepreneurship \&Regional Development 11: 269-280. 